\title{
Assessment of Residual Stresses due to Cold Bending Structural Steel Girders using Finite Element Modeling
}

\author{
By Issam Tawk ${ }^{*}$ \\ Jihad Rishmany ${ }^{\dagger}$ \\ Antoine Gergess
}

Cold bending is sometimes used for curving structural steel girders in horizontally curved structures. Although the process is simple and cost effective, it is not widely adopted yet due to the ambiguity in estimating residual stresses induced at the end of the bending process that could be relatively high. This paper focuses on assessing the magnitude of these residual stresses for a proprietary cold curving technique using nonlinear finite element analysis. For this purpose, a three-dimensional non-linear Finite Element model is developed for an IPE 600 standard symmetrical steel shape using shell elements and MSC-SimXpert analysis software. In the finite element model, bending (post-yield) loads are applied at specified intervals along the girder length, starting at one end of the girder and moving to the other end and the curved shape develops as a series of short straight segments as a function of the induced residual deformations. The effect of varying some of the key parameters (e.g. magnitude of applied loads, loading sequence and spacing between end supports) on residual stresses is then investigated and recommendations are suggested for inducing practical ranges of curvatures with acceptable limits for residual stresses.

\section{Introduction}

The cold bending process is not yet widely adopted in the steel industry for curving steel plate girders especially for applications requiring tight curvatures due to possible cracking and localized damage of the steel section in the plastic range. Alternatively, cut curving and heat curving are mostly employed especially for curving steel bridge plate girders. Cut curving can result in significant scrap whereas the heat curving process is costly and time

\footnotetext{
*Assistant Professor, University of Balamand, Lebanon. ${ }^{\dagger}$ Assistant Professor, University of Balamand, Lebanon. *Professor, University of Balamand, Lebanon.
} 
consuming due to the several heat/cool cycles required to achieve the desired radius of curvature.

Since cold bending relies on plastic strains, residual stresses develop in the steel section after bending. As a matter of fact, residual stresses exist in straight fabricated girders, especially if hot-rolled, due to thermal effects as the section is cooled down. The influence of residual stresses on the behaviour of steel members in service (after fabrication) is not negligible and their effects vary depending on their source of origin and distribution in the cross section. Residual stresses that build in the straight fabricated girder has been extensively researched and incorporated in the design methodology and standards for steel construction (Hadjoannou et al., 2011)

Pertinent information on the consequences of cold curving on the structural steel element and material properties can be found in engineering journals such as: Bjorhovde for wide flange shapes (Bjorhovde, 2006), Paulsen et al. for rectangular hollow sections (Paulsen et al., 2001) and Hadjoannou et al. for curving I-Section steel members using three-roller bending (Hadjoannou et al., 2011).

This paper deals with a proprietary cold bending system that was developed by a US steel fabricator for curving the steel plate girders of the Miami Metromover as the tolerances required could not be achieved by cutcurving or heat curving (Klobuchur, 2002). The proprietary system is simple as it separately bends the top and bottom flanges of the girder at various sections along its length by applying mechanical forces in the plastic range using hydraulic jacks built-in a movable frame. Consequently, the desired curved shape develops as a series of short straight segments Figure 1.

The main parameters of the cold bending system are the magnitude of the lateral bending loads, the intervals' length and the spacing of the supporting arms of the movable frame as shown in Figure 2. A two-dimensional analytical solution was derived to determine these parameters and monitor the geometric shape of the deformed steel girder after each load application so that the desired and induced curved shapes are in accordance. Results from the analytical method were validated by comparison with experimental data for a full-scale steel girder that was tested at the US steel fabricator premises in Tampa, Florida (Gergess and Sen, 2005a; 2005b; 2006; 2007; 2008). 
Figure 1. Idealization of the Desired Curved Shape due to Cold Bending (Gergess and Sen, 2009)

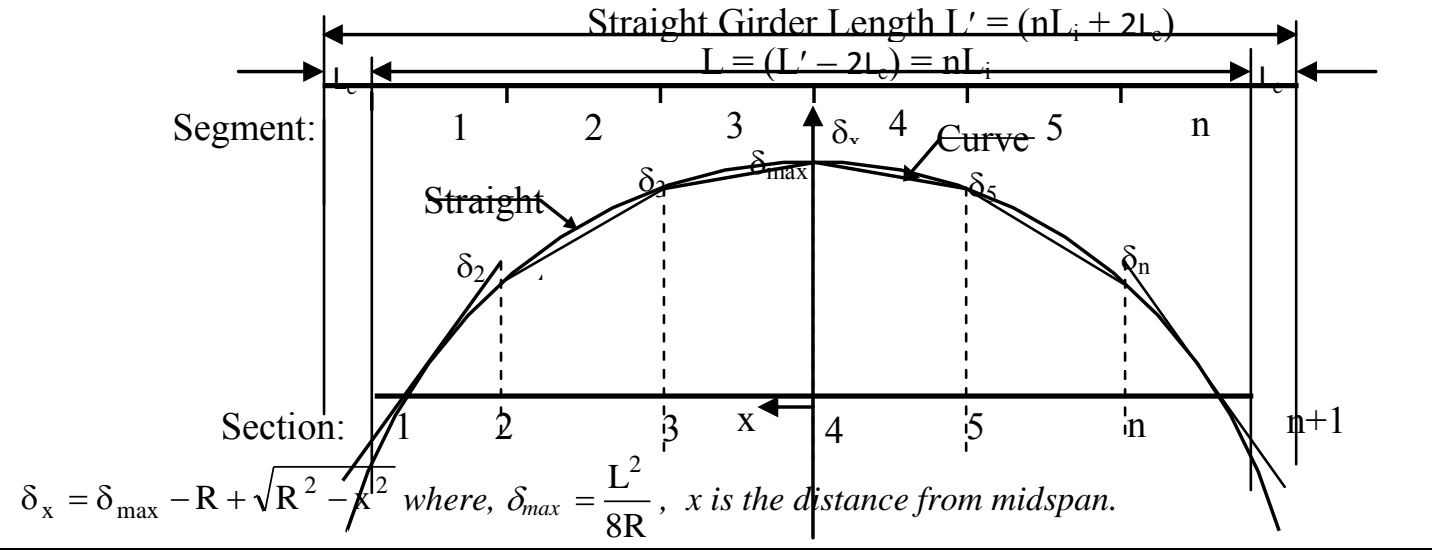

While the analytical solution ensures accuracy of the curving operation, it doesn't offer any insight into the girder's behaviour after bending, mainly the effect of the vertical web element on the deformed shape of the top and bottom flanges that are separately bent and the residual stresses that build in the steel flange and web plates after bending. Such effects (mainly residual stresses) are important for fatigue consideration, especially for steel bridges in service as they are often continuous and subjected to stress reversals.

This paper conducts a three-dimensional nonlinear finite element model for cold bending a symmetric I-girder (IPE600) considering both geometric and material non-linearities. The finite element model offers deep insight of the cold bending process, mainly on the magnitude and distribution of plastic (during loading) and residual (after unloading) stresses and strains that develop in the web and flanges of the steel section after each load application. Using FEA results, recommendations could be drawn for incorporating residual effects due to cold bending in the design of the steel curved girder in service.

\section{Girder Details and Cold Bending Cases}

The cold bending process was simulated for a symmetrical unstiffened steel girder of length $\mathrm{L}^{\prime}=6 \mathrm{~m}$ and depth $\mathrm{h}=600 \mathrm{~mm}$ Figure 2 . Both flanges are $220 \mathrm{~mm}$ wide $\mathrm{x} 19 \mathrm{~mm}$ thick, and the web plate is $562 \mathrm{~mm}$ deep $\times 12 \mathrm{~mm}$ thick. The actual yield stress (Fy) of the steel girder is 335MPa. Note that the IPE beam is a rolled steel plate section. 
Figure 2. IPE 600 beam - Girder in Vertical Position

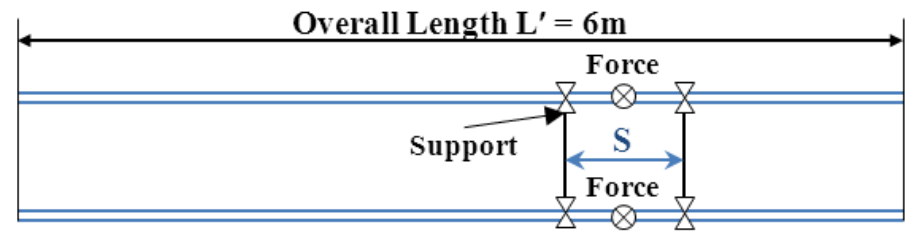

Elevation

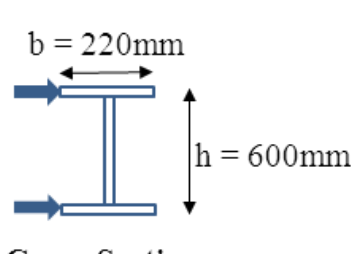

Cross-Section

Several cold bending cases were considered to obtain different radius of curvatures: 1) $\mathrm{R}=300 \mathrm{~m}, 2$ ) $\mathrm{R}=200 \mathrm{~m}$ and 3) $\mathrm{R}=125 \mathrm{~m}$ using a spacing of the loading frame $\mathrm{S}$ equal to $1350 \mathrm{~mm}$ (set based on lateral buckling of the flange, [Gergess and Sen, 2007]). The magnitude of the corresponding bending load per flange for the three cases was calculated prior to the simulation from the analytical solution based on a full plastic section at the point of application of the load (Gergess and Sen, 2007). The theoretical plastic load $\left(\mathrm{P}_{\text {theoretical }}\right)$ and corrected load $\left(\mathrm{P}_{\text {theoretical-corrected }}\right)$ are obtained based on the analytical solution (Gergess and Sen, 2007) and the dimensions of the IPE 600 beam in Figure 2. The corrected load $\left(\mathrm{P}_{\text {theoretical-corrected }}\right)$ is equal to the plastic load $\left(\mathrm{P}_{\text {theoretical }}\right)$ multiplied by correction factors that account for several geometrical nonlinearities (flange to web dimensions, shear deformations, presence of stiffeners in proximity of the applied load, etc). These are presented in Table 1 where deviations of the actually applied numerical loads in the finite element model from theoretical loads are also presented.

Differences in loads (between theoretical and numerical) may be attributed to different facts such as in the numerical model the load is applied as a distributed load while in the analytical model a concentrated load is considered. These effects are discussed in more details later on in the paper.

Table 1. Interaction between Load and Spacing

\begin{tabular}{|c|c|c|c|c|}
\hline $\mathbf{S}(\mathbf{m m})$ & $\mathbf{P}_{\text {theoretical }}$ & $\mathbf{P}_{\text {theoretical- corrected }}$ & $\mathbf{P}_{\text {numerical }}$ & Ratio \\
\hline 1350 & $228 \mathrm{kN}$ & $268 \mathrm{kN}$ & $248 \mathrm{kN}$ & $248 / 268=0.925$ \\
\hline
\end{tabular}

Detailed results are presented for the first bending operation $(\mathrm{R}=300 \mathrm{~m}$, $\mathrm{S}=1350 \mathrm{~mm}$ ) as it contains sufficient data to highlight on the three-dimensional residual effects that result from cold bending and fulfill the objectives of the paper. A summary of the results for the two other cases $(R=200 \mathrm{~m}$ and $\mathrm{R}=125 \mathrm{~m}$ ) is also presented.

\section{Finite Element Model}

\section{Introduction}

The finite element analysis was conducted using the finite element software (MSC SimXpert-2013) developed by MSC Software in which material and geometric non-linearity were considered. In the three-dimensional model, the flanges and the web were modeled using four-node isoparametric 
shell elements (CQUAD4) with in-plane bending stiffness Figure 3. The 2 flanges were $220 \mathrm{~mm}$ wide $\mathrm{x} 19 \mathrm{~mm}$ thick, and the web plate was $581 \mathrm{~mm}$ deep $\times 12 \mathrm{~mm}$ thick (a total height of $600 \mathrm{~mm}$ ). The rolled edges of the rolled IPE 600 standard symmetrical steel shape were not considered in the model.

Figure 3. FE Model of the IPE 600 beam

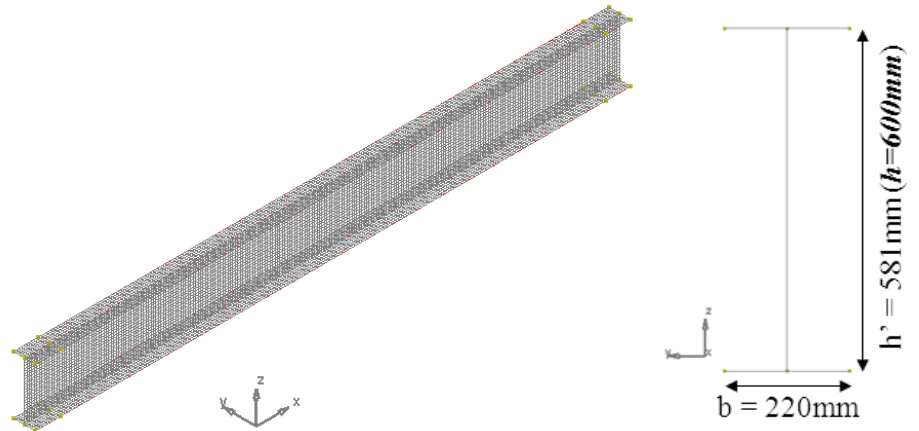

Mesh

To select an appropriate element size, a mesh sensitivity study was conducted based on a linear static analysis. Different elements sizes Table 2 were tested for various models (mesh size shown only for flange sections). Each model consisted of 2 different load cases: load case 1) which consists of a single concentrated load of $10 \mathrm{kN}$ magnitude applied simultaneoulsy to the top and bottom flanges at midlength of the girder Figure 4 and load case 2) which idealized the bending operation at midlength of the girder (a single concentrated load of $40 \mathrm{kN}$ at midspan with two reactions of $20 \mathrm{kN}$ each applied at $1 / 4$ length and $3 / 4$ length in the opposite direction, Figure 4). Accuracy of the models was confirmed by calculating the maximum lateral offset at mid-span for the two load cases Figure 4.

Table 2. Lateral Offset for Different Mesh Size

\begin{tabular}{|c|c|c|c|c|}
\hline $\begin{array}{c}\text { Mesh } \\
\text { x mm) }\end{array}$ & $\begin{array}{c}\text { Lateral offset } \\
\text { load case 1 }\end{array}$ & $\begin{array}{c}\text { Variance* } \\
\mathbf{\%}\end{array}$ & $\begin{array}{c}\text { Lateral offset } \\
\text { load case 2 }\end{array}$ & $\begin{array}{c}\text { Variance } \\
\text { \% }\end{array}$ \\
\hline $125 \times 110$ & $3.869 \mathrm{~mm}$ & NA & $6.458 \mathrm{~mm}$ & NA \\
\hline $62.5 \times 55$ & $3.944 \mathrm{~mm}$ & 1.902 & $6.543 \mathrm{~mm}$ & 1.299 \\
\hline $41.7 \times 36.7$ & $3.982 \mathrm{~mm}$ & 0.954 & $6.586 \mathrm{~mm}$ & 0.653 \\
\hline $31.2 \times 27.5$ & $4.009 \mathrm{~mm}$ & 0.673 & $6.614 \mathrm{~mm}$ & 0.423 \\
\hline $25 \times 22$ & $4.029 \mathrm{~mm}$ & 0.496 & $6.636 \mathrm{~mm}$ & 0.332 \\
\hline
\end{tabular}

*Variance between two Consecutive Mesh Sizes 
Figure 4. Mesh Senstivity: Load Cases 1 and 2

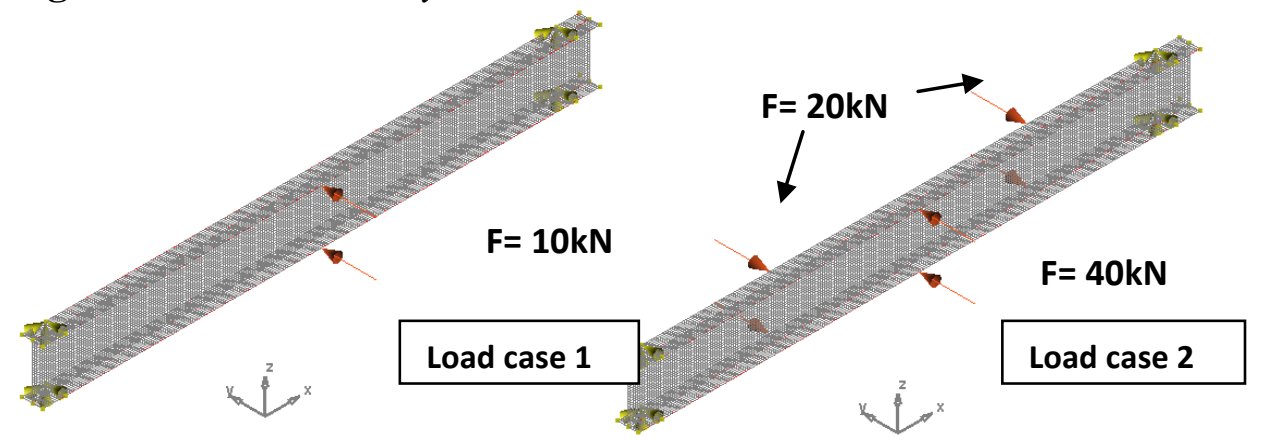

A $25 \mathrm{~mm} \times 22 \mathrm{~mm}$ (aspect ratio of 0.88 ) and a $25 \mathrm{~mm} \times 23 \mathrm{~mm}$ (aspect ratio of 0.92) element size were finally selected for the flanges and the web based on convergence of deformations as shown in Table 2 above.

The finite element mesh consisted of a total of 12150 nodes and 10800 elements Figure 4, 6000 elements for the web, 2400 elements for each flange.

\section{Material Properties}

In the finite element model, the steel stress-strain curve was idealized as elastic-perfectly plastic. A yield stress of $335 \mathrm{MPa}$ was input as a von Mises stress in the FE model. Figure 5 shows that the flat yield plateau is taken at 10 times the yield strain (Salmon and Johnson, 1996). Based on the range of the applied numerical bending loads $(\mathrm{P}=248 \mathrm{kN}$, Table 1$)$ for both flanges, it will be shown later in "section Strains" that the plastic strains that develop during bending (calculated as 3 to 4 times the yield strain) will remain within the yield plateau.

Figure 5. Idealized Stress-strain Curves (Salmon and Johnson, 1996)

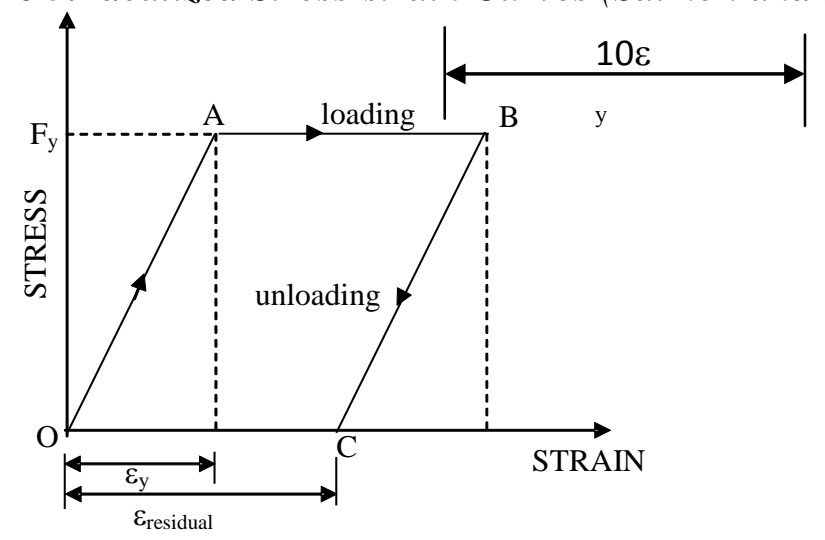

\section{Loads and Boundary Conditions}

In order to avoid localized damage, distribution plates are placed between the hydraulic jacks of the loading frame and the flanges of the steel girder. Consequently, the bending loadings are considered as distributed loads applied simultaneously to both flanges over a distance equivalent to the width of the 
distribution plate (assumed to be $150 \mathrm{~mm}$ ) in the finite element model. The supporting edges (spaced at distance $S$ ) on the opposite side of the flanges are modeled as rollers spaced at $S$ in the top and bottom flanges Figure 6 . To provide numerical stability in the $\mathrm{x}$ axis (longitudinal direction) of the finite element model, the displacement of one node is restricted in the x direction.

Figure 6. Loads and Boundary Conditions

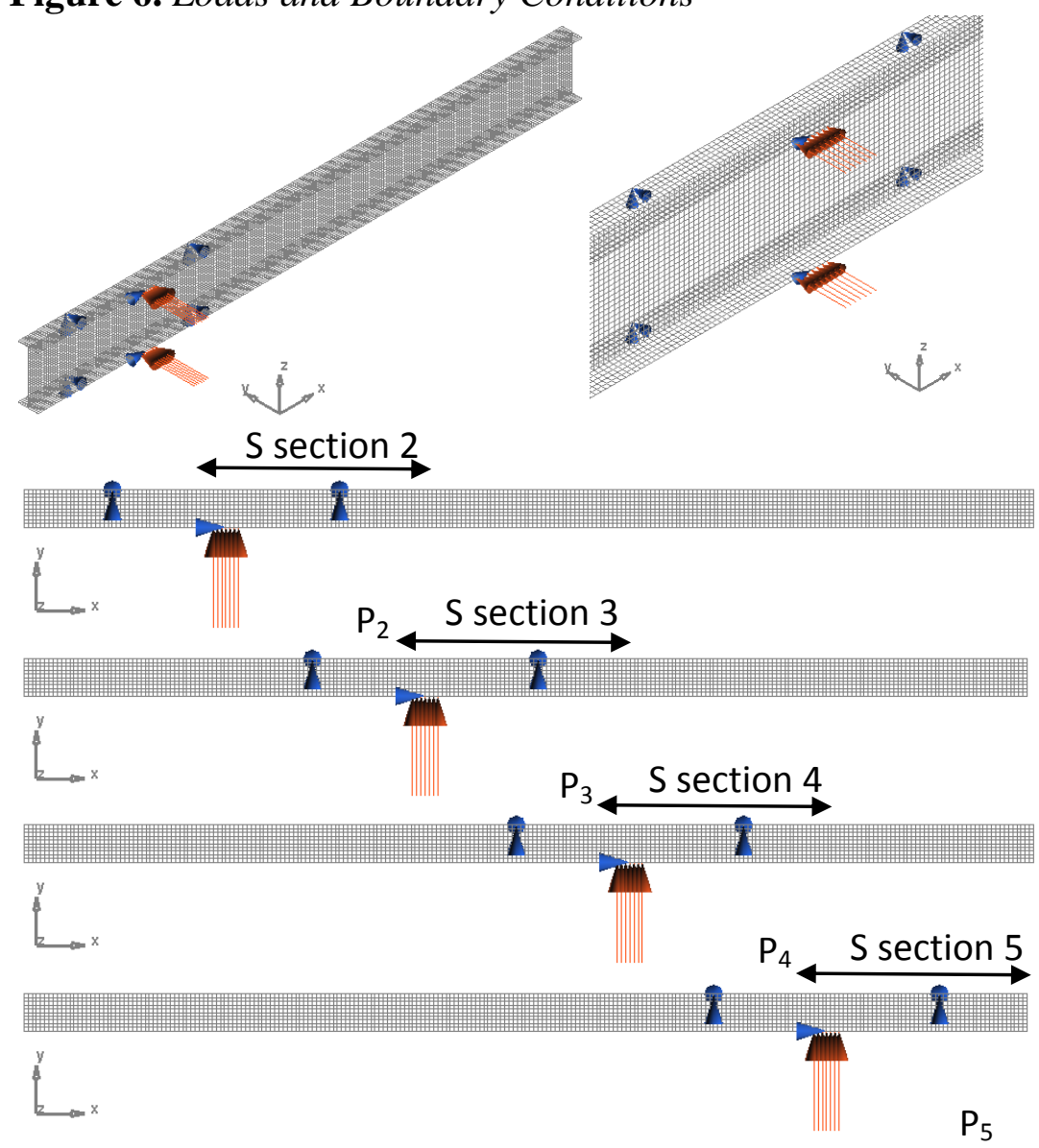

Analysis

The non-linear finite element analysis was carried out in steps to allow successive loading and unloading of the applied bending loads at different sections of the girder. The loading sequence was set identical to that from the analytical method Table 3. A total of 10 increments were used per load application with a convergence tolerance of 0.1 for displacements and 0.5 for loads. The software automatically combines results (e.g. residual deformations, residual stresses and plastic strains) from the individual steps to provide both intermediate and final results. 
Vol. 2, No. 3 Tawk et al.: Assessment of Residual Stresses due to Cold Bending...

\section{Results}

\section{Introduction}

The results shown hereafter correspond to a desired radius of curvature of $\mathrm{R}=300 \mathrm{~m}$. The spacing between supporting edges of the loading frame is $\mathrm{S}=1350 \mathrm{~mm}$ with a load of $248 \mathrm{KN}$ applied from left to right at 4 different consecutive sections labeled as $S_{2}$ (at $1200 \mathrm{~mm}$ from left end of girder), $S_{3}$ (at $2400 \mathrm{~mm}$ from left end of girder), $\mathrm{S}_{4}$ (at $3600 \mathrm{~mm}$ from left end of girder) and $\mathrm{S}_{5}$ (at $4800 \mathrm{~mm}$ from left end of girder). Since the model is symmetrical, induced lateral deformations should be equal in the top and bottom flanges (this is confirmed later by the finite element analysis). Only the offsets of the top flanges are shown from the finite element model.

\section{Comparison with Analytical Results}

Results from the 3-D finite element model were first compared against the analytical method (Gergess and Sen, 2007) which relate primarily to lateral displacements ( $\delta \mathrm{ij})$ at the flange level as shown in Figure 7 . The finite element analysis directly provides permanent deformations as they build-up after each bending operation as well as residual stresses and plastic strains. Note in Figure 7 that two curves are shown for the analytical model: a plot labeled "Analytical" based on offsets calculated at Sections S2 to S5 only and another plot labeled Analytical Smoothed that is based on plotting the equation of offsets as a function of X (abscissa axis) (Gergess and Sen, 2007).

The curves show good correlation between the Finite Element and the Analytical Method. The final shape of the girder is symmetrical. Note that lateral offsets are residual offsets that permanently build-up after the final bending load is released and the plot is based on numerical values from the finite element model recorded at each node along the length of the girder.

Figure 7. Comparison of Residual Lateral Offsets at the End of the Bending Process $(R=300 m)$

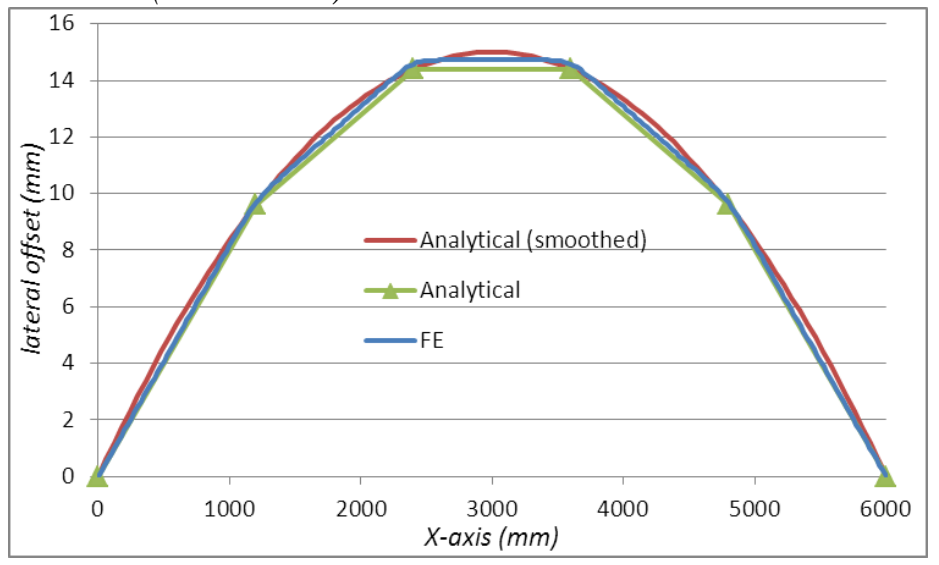




\section{Deformation}

Figure 8 shows the offset after loading/unloading from the 3-D finite element model for the different sections $\left(S_{2}, S_{3}, S_{4}\right.$, and $\left.S_{5}\right)$. The loading at each section results in a permanent deformation at each section after unloading. The build-up of the plastic deformations that develops after loading each section leads to a final symmetric shape of the girder. The deformed shape based on calculated displacements show that the desired curve can be idealized as the summation of short straight segments. Note that the lateral offsets correspond to a straight-line that connects the two ends of the beam. In Figure 8 , the $100 \%$ load means the full numerical load of $248 \mathrm{kN}$ Table 1.

Figure 8. Lateral Offset after Loading / Unlooding at Different Sections

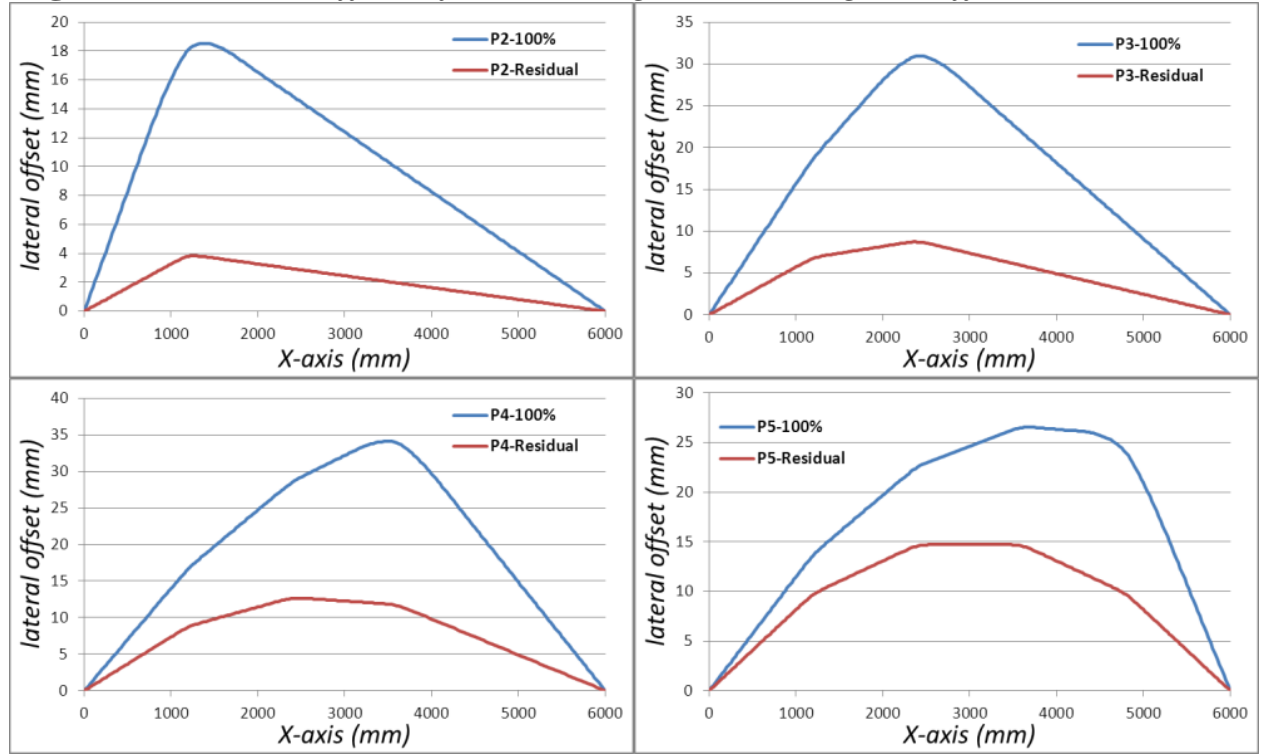

Figure 9 shows the elastic return after unloading for the different sections $\left(S_{2}, S_{3}, S_{4}\right.$, and $\left.S_{5}\right) . S_{2}$ and $S_{5}\left(S_{3}\right.$ and $\left.S_{4}\right)$ have the same elastic return of $14.29 \mathrm{~mm}(22.25 \mathrm{~mm})$. A final symmetric shape is obtained at the end of the bending process.

Figure 9. Elastic Return for the Different Sections $S_{2}, S_{3}, S_{4}$, and $S_{5}$

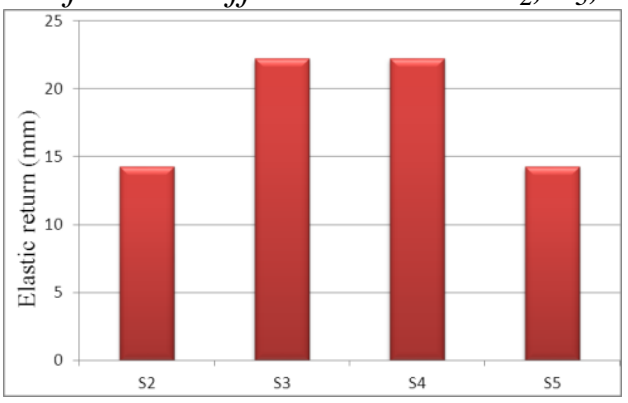

Figure 10 shows how lateral offsets develop during loading each section. Deformed shapes are shown for various bending load magnitudes (as it 
develops gradually from $20 \%$ to $100 \%$ of the numerical load of $248 \mathrm{kN}$ in $20 \%$ increments.

It may be seen from Figure 10 that the increment of lateral offsets is uniform up till $80 \%$ of the bending load (that is the load at which the seetl flange sections yield). After $80 \%$, the increase in offsets is more noticeable due to inelastic behavior of the steel flange plate sections.

In Figure 10, bending loads are labeled per section (for example P2-60\% corresponds to $60 \%$ of the bending load applied at section 2 for the top and bottom flanges).

Figure 10. Lateral Offset Evolution during Loading at Different Sections

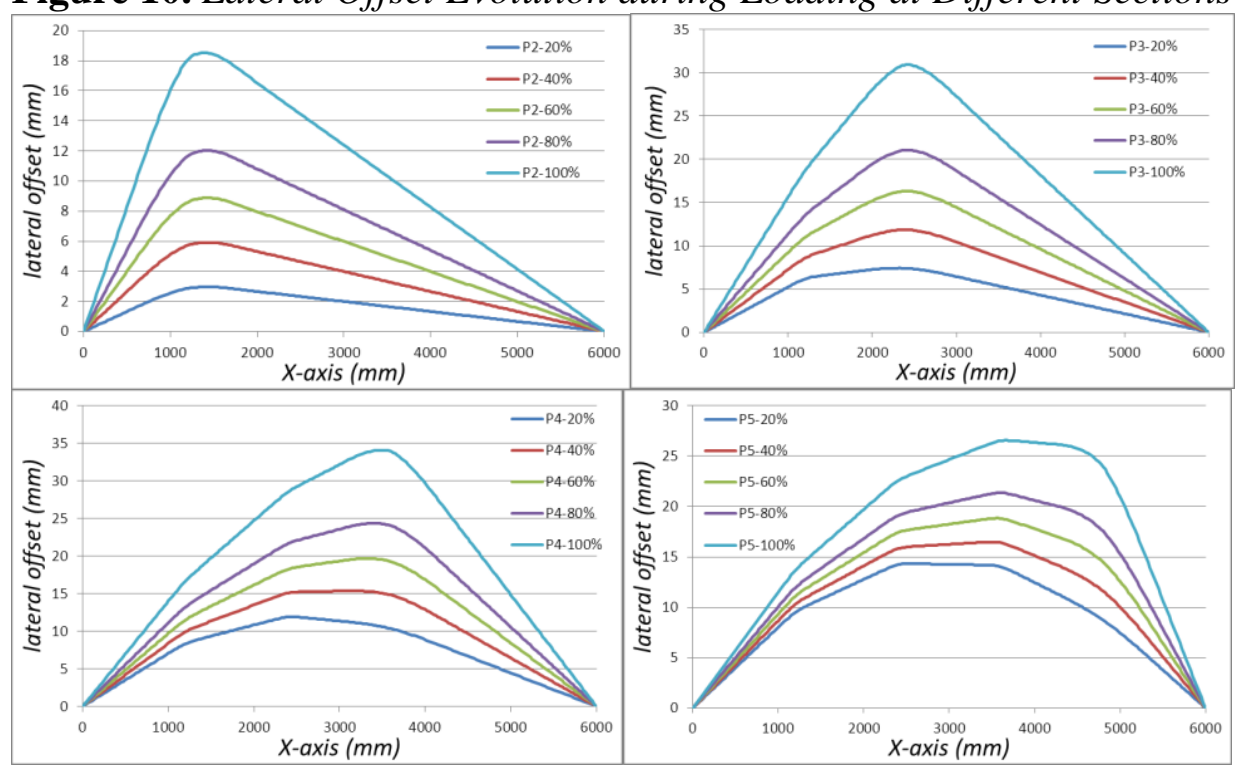

Figure 11 shows the lateral offset that build-up in the steel flange sections for different phases of loading (offsets are shown at the section where the load is applied e.g. section 2 for $\mathrm{P} 2$, section 3 for P3, section 4 for $\mathrm{P} 4$ and section 5 for P5). It can be seen from Figure 11 that non-linearity due to post-yielding occurs after $80 \%$ of the bending load for each section.

Figure 11. Lateral Offsets at (20-40-60-80-100)\% of the Load

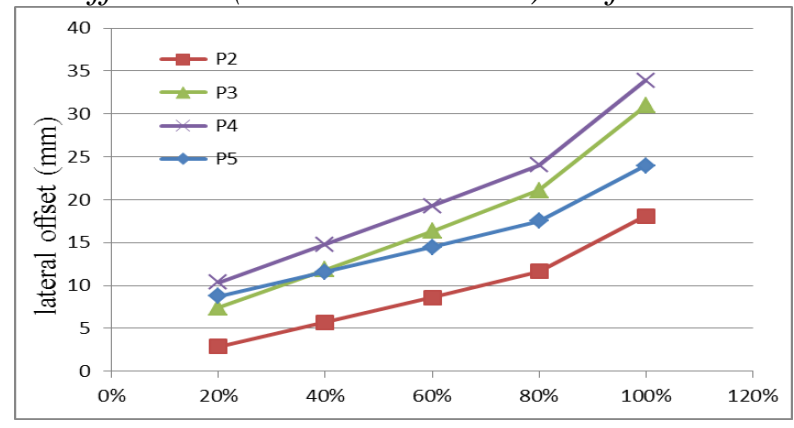


The residual offset that builds up after bending section 5 is of particular importance as it dictates the final curved shape of the girder Figure 12 which shows a final symmetric profile.

In conclusion, the finite element model is used to investigate threedimensional effects that cannot be provided by the analytical model. It should be noted that most girders have initial residual stresses built-in from fabrication of the straight girder which would affect its structural behavior during bending. In absence of data, these were not considered in the analysis.

Figure 12. Residual Lateral Offsets after each Bending Application

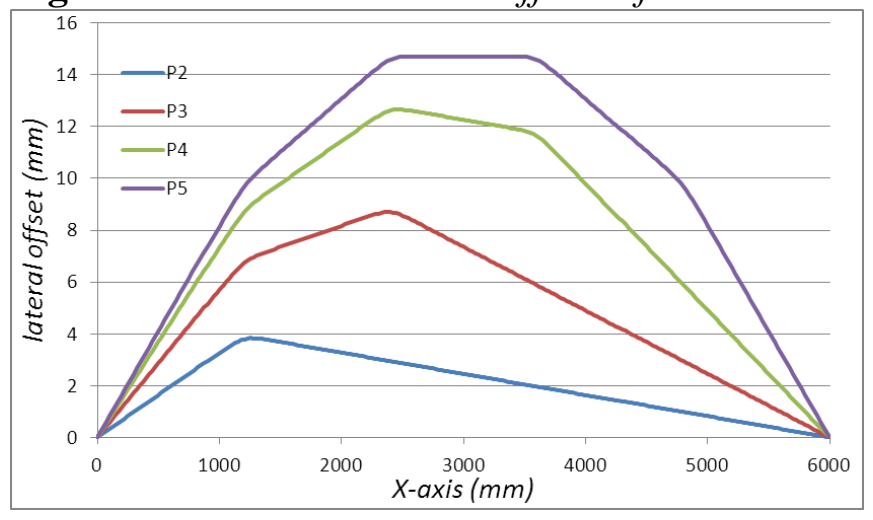

\section{Stress}

The Von Mises stresses that develop due to load $\mathrm{P}_{2}$ (gradually increased from $20 \% \mathrm{P}$ to $100 \% \mathrm{P}$ ) are shown in Figure 13. The scale limits for the 5 cases of loading were set between 0 and $335 \mathrm{MPa}$ (Yield stress). The von mises stress reaches the yield stress at about $80 \%$ of the load for both flanges and it initiates at the point of application of the load. At $100 \%$ of the bending load, the yielding zone propagates in the flange sections in the longitudinal direction. Note that the stresses near the web (at the neutral axis of the flanges) remained below the yield stress. This same behaviour is noticed for the other sections during loading. 
Figure 13. Von Mises Stress at 20-40-60-80-100\% P2

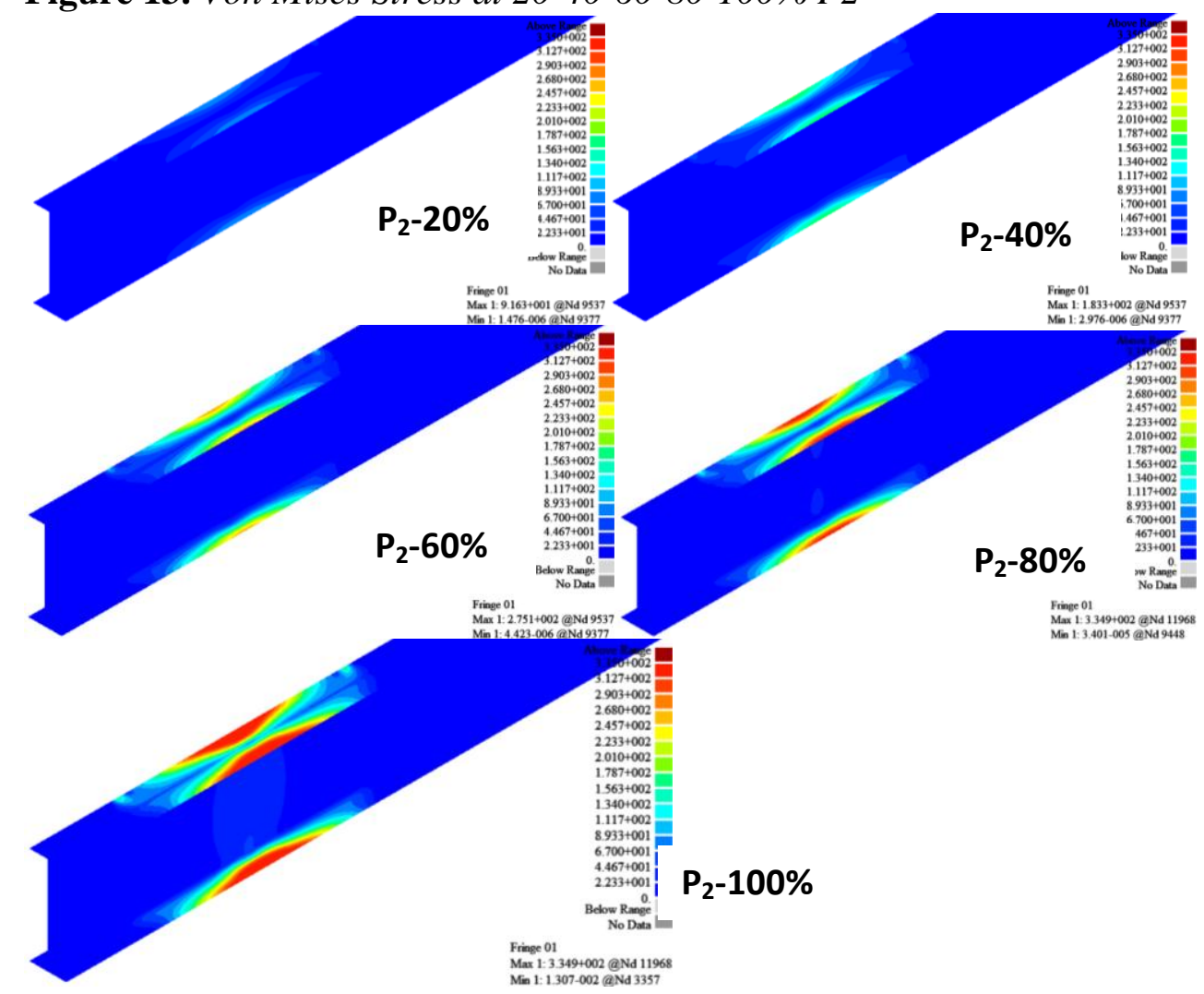

The maximum residual stresses that build in the girder after removal of the bending loads are shown in Figure 14. The stress distributions are provided at section 2 and for all the sections at the end of the bending process. The maximum residual stresses in all sections are of the same magnitude (about $123 \mathrm{MPa})$.

Figure 14. Residual Von Mises Stress Section2 / All Sections

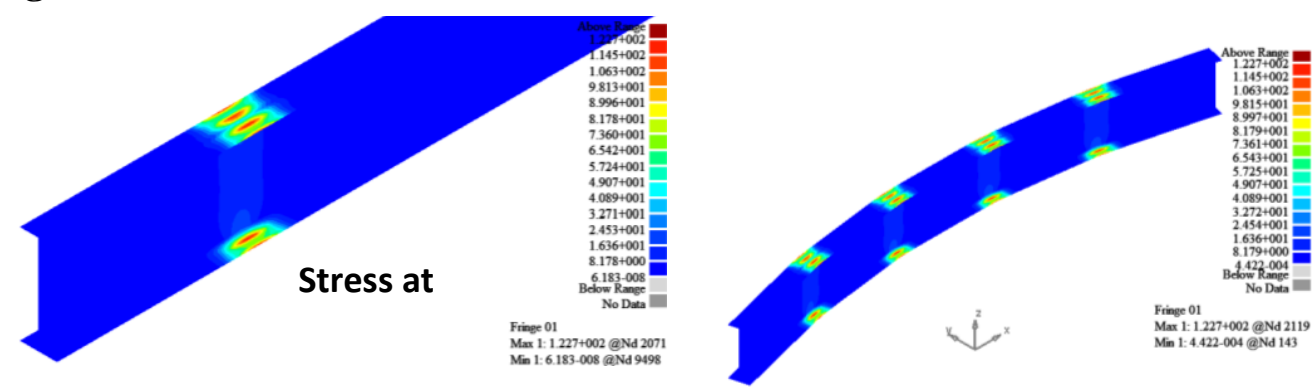

Figure 15 shows the stress distribution within the load frame spacing $\mathrm{S}$ in the longitudinal direction ( $\mathrm{X}$ direction) due to bending at $100 \%$ of the numerical bending load. These stresses are of particular importance as they should be considered in the design of steel girder unders service loads. The maximum stresses are concentrated for both flanges at the point of load application. Slight increases of $2 \%$ and $10 \%$ in the yield stress in tension 
(337MPa) and compression (-371MPa) were noted respectively (as yielding is based on the Von Mises stress criteria). The maximum residual stresses that develop in both flanges after removal of the loads are $(-130 \mathrm{MPa} \approx 0.39 \mathrm{Fy})$ in compression and $(123 \mathrm{MPa} \approx 0.37 \mathrm{Fy})$ in tension. The residual stresses in the web did not exceed $30 \mathrm{MPa}$.

Figure 15. Stress-X Direction: at $100 \% P_{2}$ / Residual of $P_{2}$

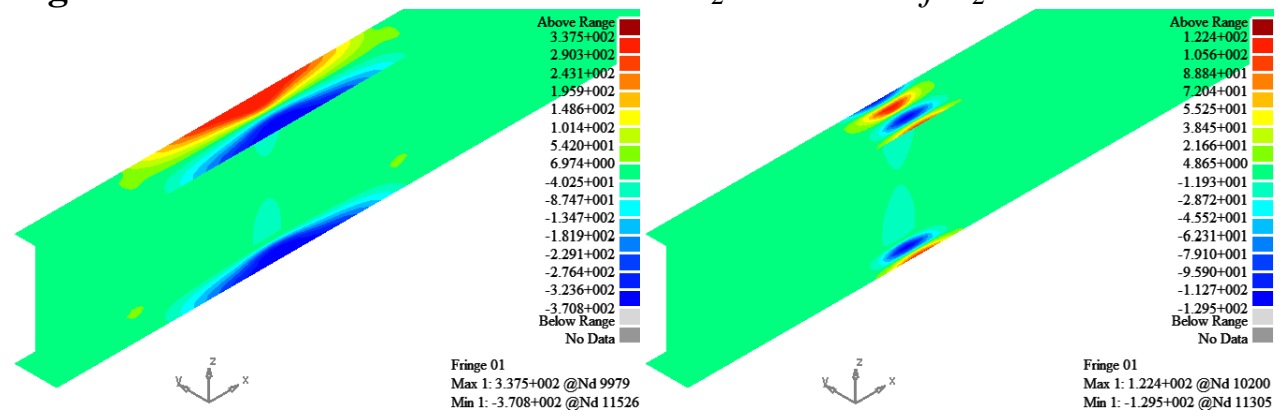

Figure 16 shows the residual Von Mises stresses in isomeric view (magnitude varies between 30 and $123 \mathrm{MPa}$ ). This figure highlights the presence of the stresses in the flanges of the specified sections. Note that at different locations the residual stresses in the web did not exceed 30MPa.

In summary, residual stresses that build up from cold bending are of significant order and if they are not released by heat treatment, they should be included in the service load design of the curved steel girder as they will affect the initiation of yield at the flange tips.

Figure 16. Residual Von Mises Stresses at the End of the Bending Process

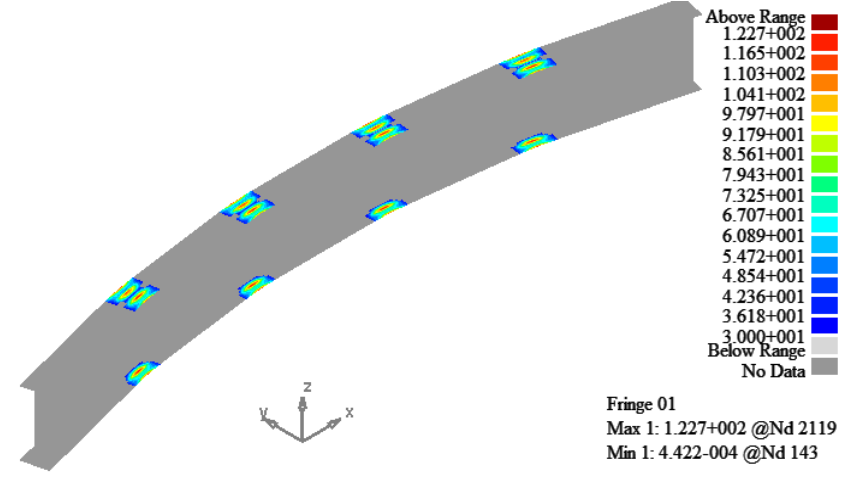

\section{Strains}

The strain distributions are presented in Figure 17 for the case when the bending load is applied at section 2. Residual strains that persist after removal of the load are shown in Figure 18.

The maximum strain that develops in both flanges during bending is $0.004608 \mathrm{~mm} / \mathrm{mm}$ (that is 2.75 times the yield strain of $0.001675 \mathrm{~mm} / \mathrm{mm}$ ). The residual strain that remains in the section after removal of the bending load is $0.00234 \mathrm{~mm} / \mathrm{mm}$ for both flanges $(1.397 \times$ yield strain $)$. 
In all cases the maximum strain is smaller than $10 \times$ yield strain (limiting strain for the flat yield plateau) Figure 5 and the loss in strain due to elastic rebound during unloading is around $1.354 \times$ yield strain.

Figure 17. Strain Distribution in the X-Direction 20-40-60-80-100\% P2

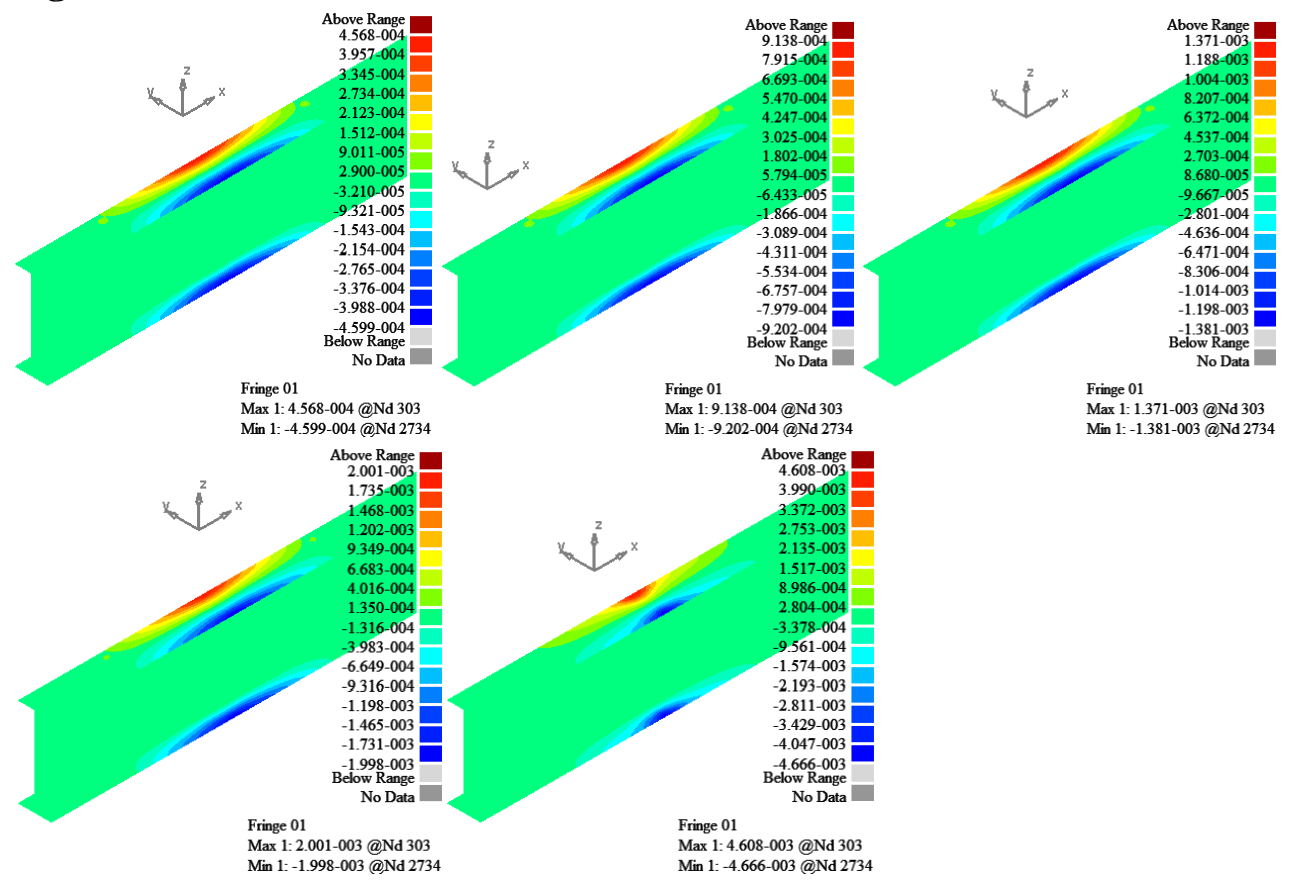

Figure 18. Residual Strain in the X-Direction - Section2 / All Sections

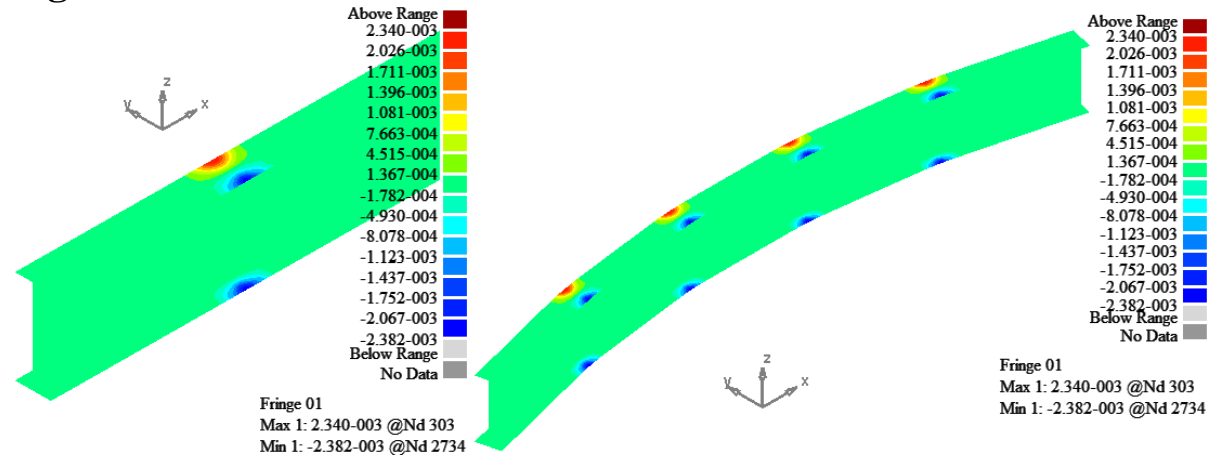

\section{Synthesis}

As mentioned earlier, the study presented in this paper investigated various loading frame configurations and radii of curvature. Results from varying the loading sequence and the spacing between the supporting arms on the deformed shape and induced residual stresses are presented in the following sections. Results are also shown for the cases where the desired radius of curvature is reduced. 


\section{Influence of Changing the Spacing of the Load Frame}

This section shows the impact of changing the distance between supports on the deformed shape of the girder and on residual stresses. The distance between the rollers $S$ was modified to $S=1250 \mathrm{~mm}$ Figure 6 . The bending load magnitude was calculated as $\mathrm{P}=225 \mathrm{KN}$. Surprisingly, the numerical load for the reduced spacing is equal to $77 \%$ of the analytical corrected load for $\mathrm{S}=$ $1250 \mathrm{~mm}$ compared to $93 \%$ for $\mathrm{S}=1350 \mathrm{~mm}$. This condition resulted in the same number of intervals $n=5$ (e.g. 4 loaded sections) for the same output radius $\mathrm{R}=300 \mathrm{~m}$. Apparently, when the frame spacing reduces, the applied bending load can be smaller than the plastic load to induce a radius of the same magnitude for the case where the frame spacing $S$ is increased. This will be investigated thoroughly in future publications.

Numerical analysis also showed that the residual stresses were about 124MPa for both flanges Figure 19, which are comparable to the stresses based on $\mathrm{S}=1350 \mathrm{~mm}$ Figure 14 .

Figure 19. $S=1250 \mathrm{~mm}$ : Residual Von Mises Stresses

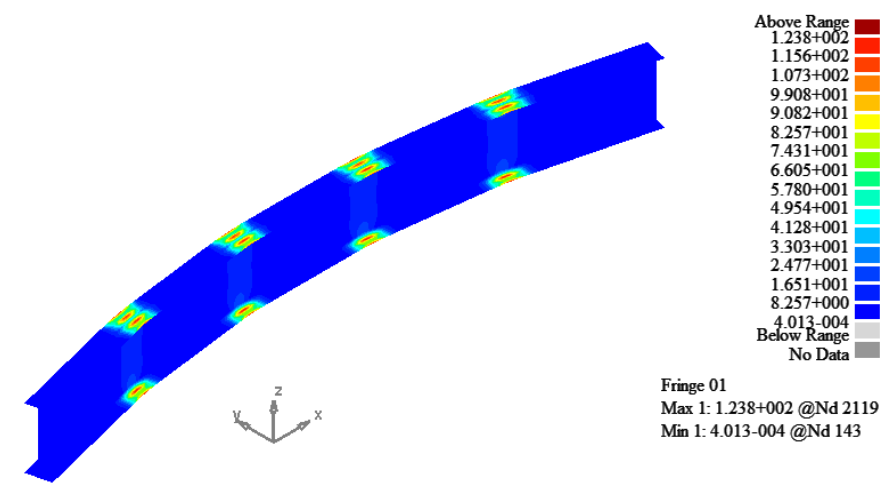

\section{Influence of Changing the Loading Sequence}

This section investigates the effects of changing the loading sequence on the deformaed shape. A summary of the loading sequences investigated is presented in Table 3. In the intial load sequence, the loading is applied sequentially from left to right, starting at section 2 and ending at section 5 .

Table 3. Tested Load Sequences

\begin{tabular}{|c|c|}
\hline Load Sequence & Order of application of the loading \\
\hline Initial Load sequence & $\mathrm{S}_{2}, \mathrm{~S}_{3}, \mathrm{~S}_{4}, \mathrm{~S}_{5}$ \\
\hline Load sequence 1 & $\mathrm{S}_{2}, \mathrm{~S}_{4}, \mathrm{~S}_{3}, \mathrm{~S}_{5}$ \\
\hline Load sequence 2 & $\mathrm{S}_{3}, \mathrm{~S}_{4}, \mathrm{~S}_{2}, \mathrm{~S}_{5}$ \\
\hline Load sequence 3 & $\mathrm{S}_{2}, \mathrm{~S}_{4}, \mathrm{~S}_{5}, \mathrm{~S}_{3}$ \\
\hline
\end{tabular}

The obtained results shows that changing the loading sequence did not affect the results (mainly the deformed shapes, residual stresses and strains). Note that in these loading seqeunces the magnitude of the bending loads was set at $248 \mathrm{kN}$.

In summary, varying the loading sequence did not impact the bending operation. However, for industrial applications, the initial loading sequence 
used (from left to right) is more practical as it makes it easier to monitor progress of offsets.

\section{Influence of Reducing the Desired Radius of Curvature}

In this section, the impact of reducing the desired radius of curvature on the bending operation is investigated. The parameters required for the bending operation are summarized in Table 4. For a Radius of $200 \mathrm{~m}$, the number of intervals is $\mathrm{n}=7$ (6 different sections, interval length $\mathrm{Li}=850 \mathrm{~mm}$ and edge distance $\mathrm{Le}=0 \mathrm{~mm}$ ). For the last Radius of $125 \mathrm{~m}$, the distance $\mathrm{L}$ is decreased from $6000 \mathrm{~mm}$ to $5500 \mathrm{~mm}$ (Le $=250 \mathrm{~mm})$, the number of intervals is $\mathrm{n}=10$ (9 different sections, interval length $\mathrm{Li}=550 \mathrm{~mm}$ ). The same load sequence is applied starting from left to right.

Table 4. Radius of Curvature with Different Spacing Load Sequence

\begin{tabular}{|c|c|c|c|c|}
\hline $\mathbf{R}(\mathbf{m})$ & $\mathbf{S}(\mathbf{m m})$ & $\mathbf{n}$ & $\mathbf{L}_{\mathbf{i}}(\mathbf{m m})$ & $\left.\mathbf{L}_{\mathbf{e}} \mathbf{( m m}\right)$ \\
\hline 300 & 1350 & 5 & 1200 & 0 \\
\hline 200 & 1350 & 7 & 850 & 0 \\
\hline 125 & 1350 & 10 & 550 & 250 \\
\hline
\end{tabular}

It should be noted that for the same load frame spacing $(S=1350 \mathrm{~mm})$, residual stresses and bending loads are of the same magnitude for the three radii of curvatures shown in Table 4 . However, an insignificant variation in the deformed shape between the FE model and the analytical results was noticed for the smaller radius of curvature R125m Figure 20.

Figure 20. Residual Lateral Offsets:R200m/R125m

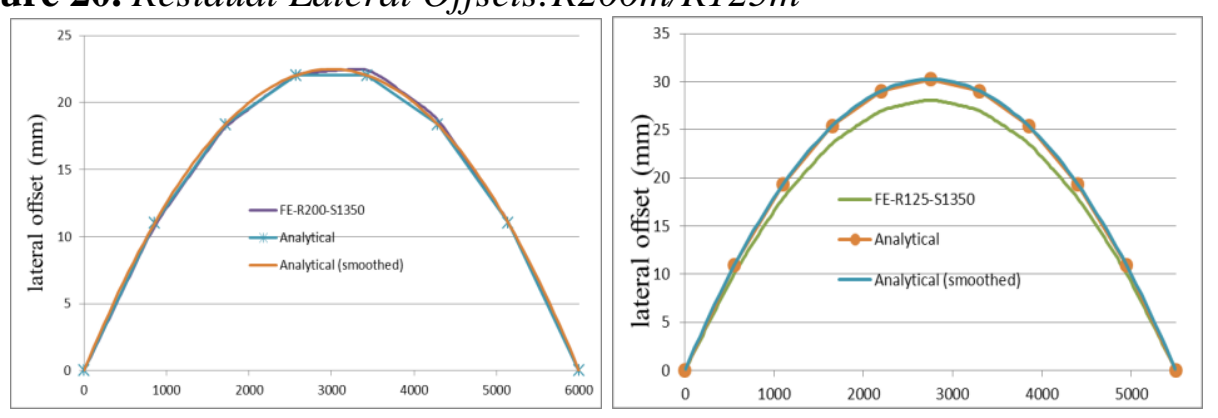

\section{Conclusions}

This paper presented results from three-dimensional finite element modeling of a IPE600 steel plate girder curved using a proprietary cold bending system. The commercially available finite element program MSC SimXpert was used for this purpose as it has the ability to account for both material and geometric non-linearity. The steel girder flanges and web were modeled using four-noded isoparametric shell elements with in-plane bending stiffness. The finite element model was compared against results from a previously developed analytical model. 
The finite element model was used to accuratley predict the progress of development of deformations and to assess residual stresses and plastic strains which directly affect the structural performance of the girder under service loads. Analysis showed that the top and bottom flange permanent deformations are equal and that the deformed shapes are symmetrical. It was also shown that the maximum strains were within the flat yield plateau of the stress-strain curve and that residual stresses were of relatively large magnitude. The maximum residual stresses were noted in the flanges near the loaded sections (around $123 \mathrm{MPa}$ in tension $(0.36 \mathrm{Fy})$ and $130 \mathrm{MPa}$ in compression $(0.388 \mathrm{Fy})$ at the flange tips).

The implications of changing the loads sequence/ spacing conditions were also examined for the Radius of curvature of $300 \mathrm{~m}$. It was shown that no major modifications in final deformed shape or in the magnitude of residual stresses ocurred. It was also noted that for a desired radius of curvature $(\mathrm{R}=125 \mathrm{~m})$, a small difference in the deformed shape between the FE model and the analytical method was observed.

Despite the lack of more precise test data for cold bending procedure, results presented in this paper provide indications on cold bending residual stresses and plastic strains that affect the design of the curved girder. Further refinements of the cold bending operation and parametric studies are planned for different Radius of curvature with different geometrical properties.

\section{References}

Bjorhovde R., Cold Bending of Wide-Flange Shapes for Construction, Engineering Journal, fourth quarter, 2006, 271-286.

Gergess A. and Sen R. Fabrication of unsymmetrical curved plate girders by cold bending (2005a). Journal of Constructional Steel Research, 61: 1353-1372.

Gergess A. and Sen R. Cold bending symmetric un-stiffened I-girder (2005b). Journal of Constructional Steel Research, 61: 473-492.

Gergess A. and Sen R. Refined analysis for cold bending steel plate girders, 2006. Journal of Constructional Steel Research, 63: 667 - 676.

Gergess A. and Sen R. Full-scale cold bending demonstration test, 2007. Journal of Constructional Steel Research, 63: 1295 - 1304.

Gergess A. and Sen R. Cold curving steel bridge girders, 2008. Transportation Research Record No. 2081, Construction, pp. 165 - 175.

Gergess A., and Sen R., Cold Bending HPS 485W Steel Bridge Girders (2009). Journal of Constructional Steel Research, Vol. 65, Issue 4, June, Elsevier Science Ltd. pp. 1549 - 1557.

Hadjoannou M., Douthe C. and Gantes C. Influence of residual stresses induced by cold curving on the resistance of I-Section steel members. Eurosteel 2011, Aug 2011, Hungary. pp. 729-734.

Klobuchur, C. Cold Bending - Tampa Steel's Experience. Presented to AASHTO/ NSBA Research \& Technology Sub-Committee, Orlando, FL, April 2002.

MSC software, The MacNeal-Schwendler Corporation (2013). "Finite Element Modeling and Postprocessing System", Santa Ana, California. 
Vol. 2, No. 3 Tawk et al.: Assessment of Residual Stresses due to Cold Bending...

Paulsen F., Welo T. and Sovik O.P., A design method for rectangular hollow sections in bending, Journal of Materials Processing Technology 113 (2001), 699-704.

Salmon C.G and Johnson, J.E. Steel Structures: Design and Behavior, Harper-Collins, NY, NY, Fourth Edition, 1996. 